\title{
A QUÍMICA NO COTIDIANO: CONTEXTUALIZANDO A TEMÁTICA DE FUNÇÕES ORGÂNICAS NUMA TURMA DE JOVENS E ADULTOS
}

\author{
Apresentação: Comunicação Oral \\ Mayzza Márcia Araújo do Nascimento; Carlos Alberto da Silva Júnior²; Flávia Rhuana \\ Pereira Sales ${ }^{3}$; Alessandra Marcone Tavares Alves de Figueiredo ${ }^{4}$.
}

\begin{abstract}
Resumo
A educação brasileira encontra-se deficitária, uma vez que ainda se permeia apenas a utilização de métodos tradicionais de ensino nas escolas. Grande parte dos docentes acredita que a forma correta de ensinar é ministrar os conhecimentos com aulas genuinamente expositivas (oratória, quadro e giz), sem a associação das vivências dos alunos. Essas dificuldades não atingem exclusivamente o Ensino Médio regular. $\mathrm{O}$ quadro se torna mais agravante quando nos referimos a Educação de Jovens e Adultos - EJA, visto que é um público multifacetado com uma base escolar ineficiente, que não concluiu em tempo hábil seus estudos. A maioria dos docentes não percebe a singularidade desses alunos e acabam inviabilizando ainda mais a compreensão dos conceitos, quando elegem a metodologia tradicional como ferramenta de ensino. Assim, esse trabalho foi desenvolvido por um grupo de pesquisa do PIBIC/CNPq locado no Instituto Federal de Educação, Ciência e Tecnologia da Paraíba - IFPB e aplicado em uma turma de 13 alunos do $2^{\circ}$ ciclo da EJA, pertencente a uma escola pública do município de João Pessoa-PB, com o intuito de facilitar o processo de ensino aprendizagem na disciplina Química, por meio de instrumentos metodológicos que apropriassem os conceitos químicos à vivência dos estudantes. O conteúdo abordado neste estudo foi Funções Orgânicas. Foram usadas as pesquisas qualitativa e quantitativa, de cunho participante. Para tal, se utilizaram de recursos midiáticos, slides e vídeos, assim como experimentos, explorando teoria e prática, concomitantemente. Para a coleta dos dados foram obtidos registros de áudio, por meio de gravações ao decorrer da aplicação e um questionário inicial (QI) abordando a temática. Os resultados foram satisfatórios, visto que os próprios discentes buscavam significância às informações adquiridas, por meio de suas vivências, participando ativamente de todo o processo. Essa metodologia diferenciada comprovou que a contextualização, por meio da problematização do cotidiano e da experimentação, gerou um diálogo motivacional e eficiente, corroborando para uma construção do conhecimento com significado.
\end{abstract}

Palavras-Chave: Ensino de Química, Educação de Jovens e Adultos, Contextualização, Experimentação.

\section{Introdução}

O setor educacional vem sofrendo mudanças significativas, mundialmente, ao longo

\footnotetext{
${ }^{1}$ Licenciatura em Química, IFPB, E-mail, mayzzaaraujo.quim@hotmail.com

${ }^{2}$ Licenciatura em Química, IFPB, E-mail, carloschemistry@icloud.com

${ }^{3}$ Licenciatura em Química, IFPB, flavia.rhuana@outlook.com

${ }^{4}$ Doutora em Química, IFPB, alessandratavaresfigueiredo@ifpb.edu.br
} 
dos séculos, porém na educação brasileira ainda permanecem os métodos tradicionais de ensino (retórica, quadro e giz), os quais tendem a minimizar as interações entre professor/aluno e aluno/aluno em sala de aula, pois o docente acredita que ministrando os conhecimentos com aulas puramente expositivas, despertará o interesse do alunado e este compreenderá o conteúdo abordado. Além disso, diversos outros fatores influenciam as problemáticas existentes no âmbito escolar, como a falta de investimento salarial para os docentes, a falta de programas com incentivo e capacitação à docência, fatores sociais, entre outros.

Nesse sentido, o ensino regular nas escolas públicas apresenta diversas dificuldades quanto à construção de conhecimentos, devido aos problemas supracitados. Com o avanço da tecnologia, muitas crianças, adolescentes e adultos não possuem a motivação para o estudo, pois muitas vertentes sociais e tecnológicas ocupam praticamente toda a atenção desses indivíduos.

Não tão obstante, o quadro é mais periclitante quando nos referimos a Educação de Jovens e Adultos - EJA, visto que é um público heterogêneo que possui uma base escolar ineficiente, que não concluiu em tempo hábil seus estudos, devido a alguns motivos, entre eles: a obrigação de trabalhar desde cedo, pois muitos cidadãos servem de muro de arrimo para a família; gravidez na adolescência; dentre outras situações que os levaram a recorrer a essa modalidade para tentar suprir a falta de escolaridade adquirida no decorrer dos anos. Esses motivos acabam afastando esses jovens e adultos da sala de aula.

A modalidade de ensino EJA oferece a oportunidade de conclusão, tanto do Ensino Fundamental, como do Ensino Médio, para aqueles que não conseguiram terminar os estudos em tempo regular (jovens e adultos). Tal modalidade se caracteriza por ser inclusiva, porém, a maioria dos docentes não percebe a singularidade desse público e acaba dificultando ainda mais a compreensão dos conceitos, a partir do uso de uma metodologia tradicional, sobretudo, acaba afastando esses alunos da sala de aula, provocando uma evasão.

Quando voltamos nossa atenção para o ensino de Química na EJA, a evasão durante as aulas é ainda mais proeminente, pois muitos alegam não entender a ciência e muito menos perceber a relevância de seu estudo. Sob esse viés, há uma real necessidade de uma intervenção didática a fim de adaptar as ferramentas metodológicas com o intuito de demonstrar a importância do estudo da Química.

Para isso, o docente deve moldar a linguagem utilizada, partindo dos conhecimentos empíricos dos estudantes. Isso implica dizer que os conhecimentos científicos devem estar vinculados as vivências do cotidiano do alunado, uma vez que a Química é necessária para 
explicar e/ou justificar situações do nosso dia a dia. Além disso, é uma ciência experimental, o que se permite empregar a experimentação com o propósito de coadunar a teoria abordada em sala. Com isso, outras ferramentas didáticas podem colaborar para a construção do conhecimento, como o uso das tecnologias de informação e a problematização dos contextos químicos.

Diante do exposto, essa pesquisa foi realizada numa escola pública em João Pessoa $\mathrm{PB}$, com uma turma de jovens e adultos, com o objetivo de facilitar o processo de ensinoaprendizagem em Química, por meio de instrumentos metodológicos que apropriem os conceitos químicos à vivência dos estudantes, despertando o interesse e a curiosidade do estudo dessa ciência.

\section{Fundamentação Teórica}

De acordo com a Lei de Diretrizes e Bases da Educação Nacional - LDB n 9.394/96, a Educação de Jovens e Adultos é uma modalidade de ensino destinada àqueles "que não tiveram acesso ou continuidade de estudos no Ensino Fundamental e Médio na idade própria" (BRASIL, 1996, p. 15). Em geral, são alunos que sofrem preconceitos e discriminações, e que apresentam, em sua grande maioria, situações de distorções idade-série e idade-conclusão.

Aliado a isso, por serem discentes que trazem consigo um histórico escolar de abandono, motivado, em geral, pela obrigação de trabalhar e ajudar na renda familiar frente ao crescente número de desempregos no país, se faz necessária uma abordagem contextualizada e que respeite e valorize o conhecimento popular e a vivência desses discentes. Freire (2011) vem corroborar essa ideia quando afirma que o conhecimento para se tornar mais significativo, é necessário que consideremos as experiências destes sujeitos inseridos dentro de seu contexto social.

Quanto ao Ensino de Química na EJA, se torna urgente à necessidade de se concretizar uma relação continuada entre os conteúdos ministrados em sala de aula e o "saber cotidiano". Através da vivência, o discente estará diminuindo o distanciamento dos conteúdos vistos em sala, com o que acontece no dia a dia deles, fazendo com que os conceitos estudados se aproximem das atividades diárias, levando o aluno a refletir sobre o consumo e a mudança de hábito frente à natureza, desenvolvendo um olhar clínico e mais apurado para a Química a nossa volta (NASCIMENTO, 2012).

Dentro desse contexto, a interação ou vínculo construído entre docente-discente durante as aulas favorecem a construção do conhecimento, pois quebra a ideologia de que o estudante é um receptor de conhecimento e o professor o dono do saber, prática essa definida 
por Freire (2011) como 'modelo bancário' de ensino. Desta forma, “essa visão de aprendizagem salienta a construção do significado e do conhecimento como um processo social em que os participantes, por meio do diálogo, criam um conhecimento". (SILVA; NAVARRO, 2012, p. 97).

Desse modo, a abordagem utilizada nessa pesquisa respeita as diferentes experiências e os diferentes níveis de conhecimento de cada aluno, pois o aprender dos alunos não acontecerá num mesmo tempo nem de um mesmo jeito. Independentemente da idade que o aluno irá ingressar na EJA, o professor precisa observá-lo para identificar seu estilo de aprendizagem e forma de apreender o conhecimento, para assim desenvolver as atividades diversificadas (NASCIMENTO, 2012).

Outra atividade que contribui, significativamente, para uma efetiva aprendizagem no ensino de Química, é a experimentação, somada a uma metodologia alternativa de ensino. Segundo Souza (2013, p. 29) "o uso da experimentação é uma forma de contextualizar os conteúdos de Ciências [...] relacionando-os com situações do cotidiano dos alunos". Por fim, faz-se necessário também o uso de ferramentas didáticas e pedagógicas, como as Tecnologias da Informação e Comunicação (TICs), que evidenciam estratégias e materiais de apoio inovadores. Com o uso dessas TICs é preciso incluir os discentes nessa era digital, desenvolvendo aulas motivadoras e mais dinâmicas (MESQUITA; SOARES, 2014).

A formação consciente na Educação Básica é algo crucial para todos, pois em todas as sociedades se observa cada vez mais a cobrança por competências e habilidades, assim, mesmo que o tradicional método de ensino, praticado por um grande número de docentes, contrapõe a qualquer metodologia diferenciada, necessita-se que o Ensino de Química seja de qualidade e contextualizado, respeitando, especialmente, o saber popular dos discentes, garantindo assim uma aprendizagem efetiva e significativa.

\section{Metodologia}

Este trabalho foi desenvolvido e aplicado por um grupo de pesquisa do PIBIC/CNPq locado no IFPB, campus João Pessoa. A aplicação ocorreu em uma escola estadual, situada na capital da Paraíba, em uma turma do $2^{\mathrm{o}}$ ciclo, que corresponde ao $3^{\mathrm{a}}$ ano do Ensino Médio regular, da modalidade Educação de Jovens e Adultos, do período noturno, com um espaço amostral de 13 alunos participantes.

O trabalho tem cunho participante, que segundo Brandão e Borges (2007, p. 54), o pesquisador deve "partir da realidade concreta da vida cotidiana dos próprios participantes individuais e coletivos do processo", compartilhando as vivências dos pesquisados mediante a 
observação dos fenômenos, participando, sistematicamente e permanente, ao longo do tempo da pesquisa e das suas atividades (MARCONI; LAKATOS, 2010).

Quanto à natureza da abordagem, apresenta pesquisa qualitativa e quantitativa. De acordo com Caleffe e Moreira:

\section{A pesquisa qualitativa explora as características dos indivíduos e cenários que não podem ser facilmente descritos numericamente. O dado é frequentemente verbal e é coletado pela observação, descrição e gravação. A pesquisa quantitativa, por outro lado, explora as características e situações de que dados numéricos podem ser obtidos e faz uso da mensuração e estatísticas (2008, p. 73).}

Para o planejamento dessa práxis foi analisado o conteúdo programático a ser aplicado na turma, conjuntamente ao professor regente. As aulas foram elaboradas dando continuidade ao Plano de Ensino proposto pelo professor, tendo por base o uso de ferramentas metodológicas que oportunizassem uma aprendizagem real e significativa. A aplicação da atividade deu-se durante 3 (três) aulas, com duração de 30 (trinta) minutos cada, contemplando o conteúdo Funções Orgânicas.

A execução das aulas teve como proposta a exposição dialogada dos contextos químicos durante todo o processo, com o auxílio de recurso visual midiático (slides). Além disso, utilizou-se de experimentos e vídeos explorando teoria e prática, concomitantemente. Para a coleta dos dados foram obtidos registros de áudio, por meio de gravações no decorrer de toda aplicação e um questionário inicial (QI) abordando a temática.

A sequência das aulas está elencada:

$1^{\text {a }}$ aula: $\mathrm{O}$ questionário inicial (QI) foi aplicado na turma tendo por finalidade a sondagem. Com isso, puderam-se analisar os conhecimentos dos alunos com respeito ao conteúdo já introduzido pelo professor. Essa sondagem contribuiu significativamente no planejamento das aulas.

$2^{\mathrm{a}}$ aula: A priori, foram revisados os conceitos vistos pelos alunos em aulas anteriores sobre a temática por meio de discussões. Conceitos sobre Química Orgânica, a presença do carbono nos compostos, hidrocarbonetos, foram explorados nesse primeiro momento de maneira dialogada e contextualizada. Com o intuito de reforçar a aprendizagem, foi realizado um experimento contextualizado, em sala de aula, demonstrando a presença do Carbono na sacarose $\left(\mathrm{C}_{12} \mathrm{H}_{22} \mathrm{O}_{11}\right)$, e concomitantemente apresentado um vídeo que abordava o mesmo aspecto. Para a realização do experimento foram utilizados os seguintes materiais: 1 (um) béquer (100 mL) apoiado em 1 (um) prato de sobremesa e 1 (um) bastão de vidro. Os reagentes: açúcar (sacarose), aproximadamente $50 \mathrm{~g}$, e ácido sulfúrico $\left(\mathrm{H}_{2} \mathrm{SO}_{4}\right)$, PA, aproximadamente $60 \mathrm{~mL}$. Como procedimento, colocou-se o açúcar até a metade do béquer (aproximadamente), cobrindo-o com o ácido sulfúrico. Feito isso, introduziu-se o tema de 
Funções Orgânicas, expondo definições e sua aplicabilidade.

$3^{\text {a }}$ aula: Inicialmente, houve uma breve revisão dos aspectos discutidos na aula anterior, com o intuito de nortear os alunos na aplicação. Dando continuidade, conceitos sobre o estudo das Funções Orgânicas foram explorados, por meio de discussão, com o intuito de reforçar a aprendizagem do conteúdo. Um vídeo foi apresentado contextualizando o Álcool como combustível, através de uma reportagem de um jornal conhecido nacionalmente. Feito isso, um experimento atrativo foi realizado. Para o experimento utilizou-se os materiais: 1 (um) prato de sobremesa, 1 (um) bastão de vidro e papel. Os reagentes: permanganato de potássio $\left(\mathrm{KMnO}_{4}\right)$ e glicerina ou glicerol $\left(\mathrm{C}_{3} \mathrm{H}_{8} \mathrm{O} 3\right)$. Como procedimento colocou-se uma quantidade de permanganato de potássio em cima do papel, e logo se adicionou a glicerina.

\section{Resultados e Discussão}

Em análise as respostas do QI, aplicado no primeiro encontro com a turma, foi notório que há certa deficiência por parte dos alunos em correlacionar às definições estudadas em sala de aula, com as perguntas involucradas no questionário, a exemplo da primeira pergunta: "Um composto é orgânico quando?..." A maioria apresentou dificuldade na resposta, não associando corretamente as opções disponíveis. Outra questão, de suma importância para esse estudo, referia-se à citação de algum exemplo de composto carbônico presente no dia a dia, e dentre os 13 alunos participantes, apenas $23 \%$ responderam corretamente.

Isso trouxe para o grupo uma grande preocupação, pois se percebeu que os estudantes não estavam aprendendo significativamente o conteúdo. Esse fator contribuiu na escolha dos recursos didáticos utilizados nessa aplicação. Segundo Vaitsman \& Vaitsman (2006), utilizar de metodologias que disponham os alunos diante de situações reais do cotidiano, aliadas às discussões orientadas e promovidas por intermédio de tópicos em sala e que possam ser correlacionados com a Química, contribuem significativamente para o aprendizado.

Desta maneira, buscou-se planejar a atividade dentro de uma esfera que pudesse trabalhar as competências e habilidades dos estudantes, como a compreensão e identificação das Funções Orgânicas no cotidiano (BRASIL, 2006), de modo a coadunar saber popular e saber científico, possibilitando assim aos alunos construírem seu próprio conhecimento, num dinamismo em que os mesmos fossem capazes de reconhecer a Química Orgânica no seu contexto social.

No segundo encontro com a turma, de início, os alunos foram questionados sobre o estudo da Química Orgânica: “O que efetivamente estuda a Química Orgânica? Onde encontramos compostos orgânicos no dia a dia?" Neste momento, pôde-se observar que os 
alunos não conseguiam definir precisamente o que lhes fora perguntado. Houve, portanto, a necessidade de realizar uma breve revisão do conteúdo visto em aulas anteriores.

Foi então explicado o conceito de Química Orgânica como sendo a Química dos compostos do carbono (BRUICE, 2006), e que esses compostos representam cerca de $90 \%$ de todos os compostos atualmente conhecidos, e participam ativamente do cotidiano da vida humana. Indagados se alguém tinha conhecimento de onde eram encontrados esses compostos, um aluno respondeu: "Os compostos orgânicos estão presentes então nos alimentos, produtos de limpeza, combustiveis".

Vale salientar que o conhecimento adquirido pelos discentes da EJA firma-se por intermédio das vivências individuais e da interação com o mundo em que vive e atua. Esse fato ao ser explorado pelo docente contribui na construção de um aprendizado significativo (BRASIL, 2006).

$\mathrm{Na}$ sequência, foram apresentadas imagens de produtos presentes no cotidiano, mediante o recurso visual (slides), correlacionando o conteúdo com a realidade dos alunos (Figura 1). Segundo Mercado (2002), os componentes tecnológicos devem ser explorados em sala de aula, visto que estas ferramentas possibilitam maior interesse do aluno, pois na maioria das vezes, eles são acostumados apenas com quadro e giz.

Figura 1: Apresentação dos compostos presentes no cotidiano. Fonte própria.

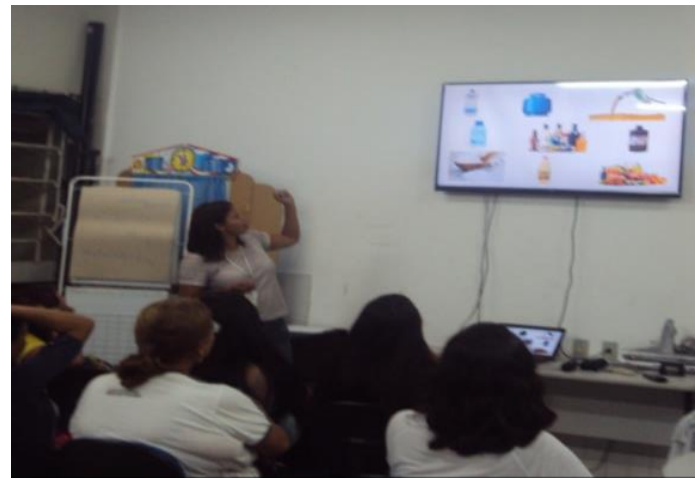

Feito isso, os alunos foram questionados sobre o que esses produtos tinham em comum. Um aluno então respondeu: “o carbono?”. Tal situação proporcionou a interação com os estudantes que, de forma dinâmica, iam participando da aplicação. Nesse momento, também foi trabalhado o contexto histórico, fazendo referência à presença constante dos compostos orgânicos na história da humanidade, a exemplo da produção das bebidas alcóolicas, o vinagre, corantes, etc.

Dando continuidade, foi realizado o experimento contextualizado, com a finalidade de demonstrar a presença do carbono nos compostos (Figura 2). Ao misturar o açúcar com o ácido sulfúrico notou-se uma mudança na coloração, passando de branca a preta, e também se 
percebeu uma liberação de vapor, assim como o aumento de temperatura. O que aconteceu: a fórmula da sacarose é $\mathrm{C}_{12} \mathrm{H}_{22} \mathrm{O}_{11}$, ou seja, há presença de carbono. Quando adicionado o ácido sulfúrico ao açúcar, após alguns segundos, houve uma desidratação da substância, liberando a água em forma de vapor, restando apenas o carvão (carbono). Também se percebeu um aumento na temperatura, caracterizando uma reação do tipo exotérmica.

Figura 2: Momento do experimento. Fonte própria.

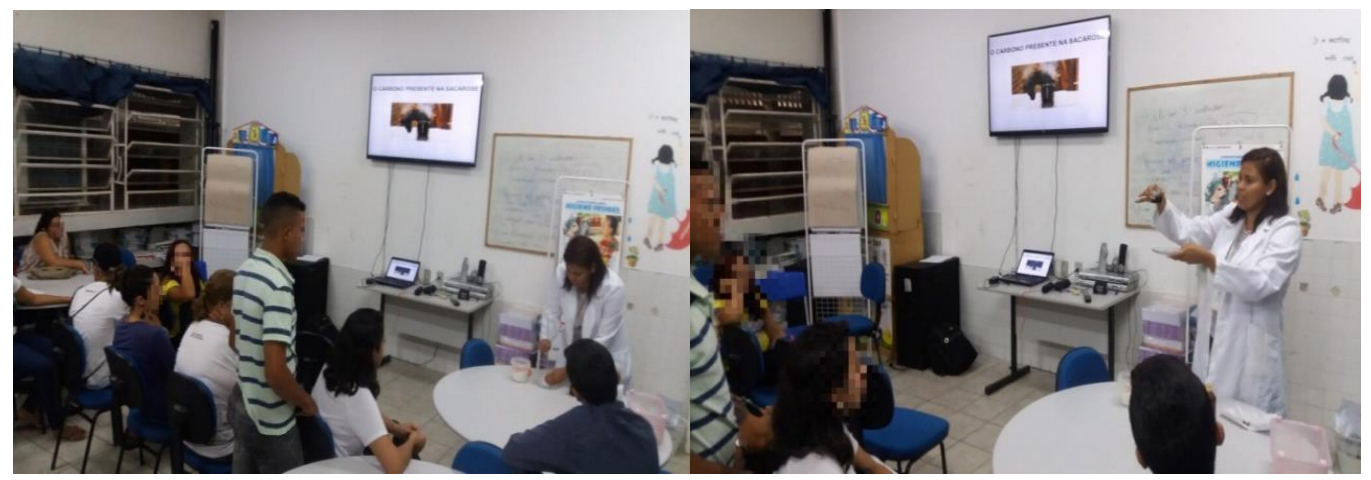

Foi perceptível o entusiasmo da turma ao visualizarem o experimento, tendo em vista que essa prática não é corriqueira em suas aulas. A turma tratava de entender o que havia acontecido no procedimento, argumentando as possíveis explicações por intermédio de perguntas do tipo: Por que o açúcar ficou preto? O que é essa fumaça que saiu do açúcar? Por que essa mistura ficou tão quente? Esses questionamentos foram respondidos mediante explicação supramencionada.

Juntamente à prática, lhes foi apresentado um vídeo que ilustra de forma enfática a desidratação do açúcar com o uso de maiores quantidades de reagentes, tendo em vista que se utilizou de uma pequena quantidade do ácido sulfúrico no experimento, por questões de segurança, uma vez que ele possui ação corrosiva nos tecidos dos organismos vivos e pode causar queimaduras severas na pele. E ainda, a manipulação do experimento foi feita, exclusivamente, pelo grupo de pesquisa, utilizando todas as normas de segurança. Os estudantes da EJA apenas observaram a experimentação, de modo a preservar a integridade física deles.

Essa prática corroborou para o que havia sido discutido teoricamente, sendo de grande valia para os estudantes, pois permitiu que os mesmos tivessem uma experiência com a química além do abstrato. A utilização de experimentos nas aulas de Química apresenta muita significância, uma vez que as práticas experimentais contextualizadas promovem aos alunos uma maior compreensão das transformações químicas que ocorrem no meio em que estão inseridos (CORDEIRO et al, 2015).

Após a aplicação do experimento introduziu-se o conteúdo de Funções Orgânicas. O 
professor da turma em aulas anteriores, de maneira introdutória, havia discutido as definições de Hidrocarbonetos, a função mais simples da Química Orgânica. Com o intuito de realizar uma breve revisão, os alunos foram questionados com a seguinte pergunta: "Quais os dois elementos químicos que compõem os hidrocarbonetos?” Um aluno então respondeu que os dois elementos eram o carbono e o hidrogênio.

Dando continuidade, lhes foi citado exemplos de compostos que faziam parte do cotidiano como o gás de cozinha, que apresenta como constituinte principal o hidrocarboneto butano $\left(\mathrm{C}_{4} \mathrm{H}_{10}\right)$, a gasolina que também é um hidrocarboneto, com fórmula molecular $\mathrm{C}_{8} \mathrm{H}_{18}$, entre outros. Foi explicado que a função hidrocarboneto não era única, mas que também havia muitas outras funções orgânicas, as quais eles conheceriam as principais, especialmente as que estavam mais presentes no dia a dia.

No terceiro encontro com a turma, fora realizada uma retrospectiva dos aspectos discutidos na aula anterior. Esse momento é de suma importância, pois a partir do diálogo o professor é capaz de reconhecer se as aulas estão, de fato, apresentando alguma significância para os alunos. Além disso, incentiva a interação e ao raciocínio dos alunos. Indagados sobre o conhecimento de compostos orgânicos presentes no nosso cotidiano dois alunos responderam:

Aluno 1: "o gás de cozinha, a acetona, o açúcar”.

Aluno 2: "o álcool, os alimentos".

Em seguida, lhes foi explicado o conceito de Funções Orgânicas, o porquê do seu estudo e qual a sua aplicabilidade. Enfaticamente, explanou-se sobre as funções orgânicas oxigenadas, visto que representam uma quantidade diversificada de compostos orgânicos (BRUICE, 2006). Isto porque, depois do carbono e do hidrogênio, o oxigênio é o elemento químico de maior presença nos compostos orgânicos. Aliado a isso, alguns exemplos de produtos que apresentavam os principais grupos funcionais foram citados, como por exemplo, a acetona, o formol, o aroma das frutas, entre outros.

Por se tratar de um tema amplo, pois existem muitos tipos de funções orgânicas oxigenadas, foi escolhida a função Álcool para a discussão, pois esse grupo está presente em diversos produtos, dando origem também a outras funções através de reações específicas. Foram considerados os três mais comuns para o estudo: o metanol $\left(\mathrm{CH}_{3} \mathrm{OH}\right)$, o etanol ou álcool etílico $\left(\mathrm{C}_{2} \mathrm{H}_{5} \mathrm{OH}\right)$ e o glicerol ou glicerina $\left(\mathrm{C}_{3} \mathrm{H}_{8} \mathrm{O}_{3}\right)$. À medida que acontecia o diálogo lhes foram apresentadas as características desses álcoois como função, extração e aplicabilidade.

O etanol ou álcool etílico é o álcool comum, de extenso uso doméstico. Uma das 
maneiras de ser preparado é através do processo de fermentação de açúcares ou cereais (BRUICE, 2006). Questionados sobre a principal matéria-prima do etanol, no Brasil, um aluno respondeu: cana-de-açúcar. Não tão obstante, existem outras fontes de matéria-prima que dá origem ao etanol. Nesse momento, com o objetivo de comprovar essa afirmação, lhes foi apresentado um vídeo (Figura 3) que relatava uma reportagem de um jornal conhecido nacionalmente enfatizando a fabricação do etanol por meio da batata doce.

Figura 3: Momento do vídeo: “A fabricação do etanol por meio da batata doce”. Fonte própria.

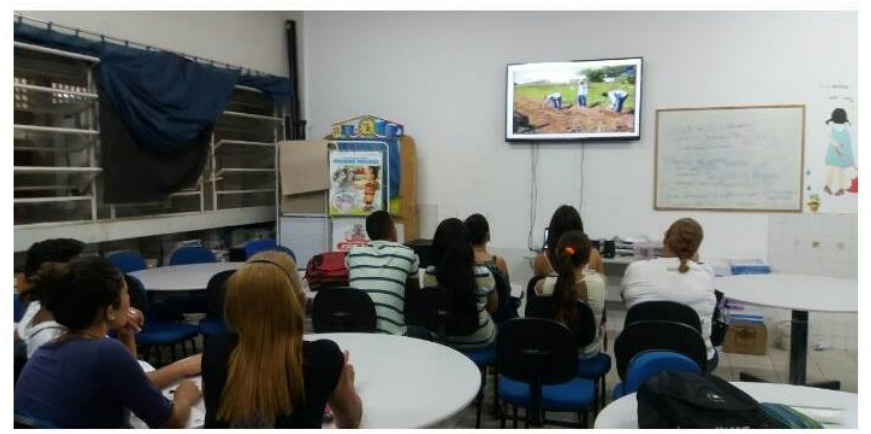

Esse vídeo despertou nos alunos a curiosidade e a vontade em dialogar sobre o tema, compartilhando ainda mais de suas experiências. Um aluno destacou um relato que passara na reportagem: "Percebi que eles falaram que além da batata tem também o milho e a soja. Eu não sabia disso". Enfatizou-se que o etanol é utilizado nas bebidas alcoólicas, como combustível, perfumes, etc.

Para finalizar a aula, foi realizado outro experimento (Figura 4) de maneira a contextualizar as características dos álcoois, como por exemplo, serem inflamáveis. Para tal, se utilizou da glicerina (glicerol) para o procedimento. Ao se misturar a glicerina com o permanganato de potássio ocorreu uma reação de oxidação com liberação de calor (reação exotérmica). O que se observou foi o aparecimento do fogo após reagirem. Esse tipo de reação também ocorre se substituir a glicerina por outros álcoois. A presença do papel serviu para intensificar o fogo gerado.

Figura 4: Momento do experimento. Fonte própria.

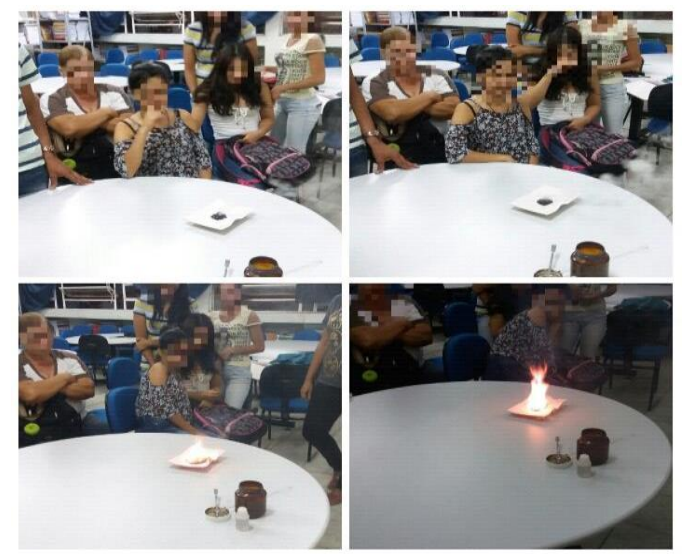


Pôde-se perceber que a prática despertou o interesse dos alunos, pois os mesmos viram-se encantados com o experimento. Além disso, o que até então era subjetivo para eles, agora possuía significado, e relacionava-se com o que era discutido em sala. Nesse momento, os alunos descreviam situações cotidianas sobre a temática, como relatam as falas abaixo:

Aluno 3: "Meu tio trabalha vendendo frutas e ele passa a glicerina pra que fiquem com mais brilhos".

Aluno 4: "Eu mesmo uso a glicerina pra limpar a geladeira. Fica brilhando!"

A participação dos alunos na atividade proposta fortaleceu o processo de ensino aprendizagem, no sentido que os próprios discentes buscavam significância às informações adquiridas, por meio de suas vivências. Essa metodologia diferenciada comprovou que a contextualização, por meio da problematização do cotidiano e da experimentação, gerou um diálogo motivacional e eficiente.

\section{Conclusões}

Essa atividade serviu de grande valia para os estudantes da EJA, tendo em vista que o objetivo principal desta pesquisa foi utilizar ferramentas didáticas que minimizassem o distanciamento dos alunos com a disciplina de Química, principalmente quando se discorre a jovens e adultos tão excluídos socialmente e culturalmente, que por estarem muito tempo longe da sala de aula, apresentam dificuldades quanto ao seu estudo. Criar métodos que proporcionem uma aprendizagem real, utilizando de analogias inseridas no contexto do aluno, explorando suas vivências, é à base dessa pesquisa.

Os recursos didáticos utilizados nesse trabalho contribuíram efetivamente para uma aprendizagem com significado, visto que os discentes se mostraram interessados, participando ativamente de toda a aplicação, em um ambiente dinâmico e interativo, gerador de debates e discussões, possibilitando a união entre ciência e cotidiano.

\section{Referências}

BRASIL. Ministério da Educação e Cultura. Série: Trabalhando com a Educação de Jovens e Adultos. Brasília: Imprensa Nacional, 2006.

Orientações Curriculares Para O Ensino Médio: Ciências da Natureza, Matemática e suas Tecnologias. Secretaria de Educação Básica. - Brasília: Ministério da Educação, Secretaria de Educação Básica, 2006.

Lei 9394/96. Diretrizes e bases da educação nacional-LDB. Brasília: MEC, 1996. Disponível em http://www.planalto.gov.br/ccivil 03/LEIS/19394.htm Acesso em: 08 de outubro de 2016. 
BRANDÃO, C. R.; BORGES, M. C. "A pesquisa participante: um momento da educação popular." Revista de Educação Popular 6.1, 2007.

BRUICE, P. Y. Química orgânica, quarta edição, volume 1 / Paula Yurkanis Bruice. - São Paulo: Pearson Prentice Hall, 2006.

CALEFFE, L. G.; MOREIRA, H. M. Metodologia da pesquisa para o professor pesquisador. $2^{\circ}$ Ed. Rio de Janeiro: Lamparina, 2008.

CORDEIRO, R. M.; et al. Uso de Atividades Experimentais no Ensino de Química na $1^{\text {a }}$ Etapa do Ensino Médio para Educação de Jovens e Adultos: Aplicação a partir da Necessidade dos Educandos. 14 Encontro de Profissionais da Química, p. 424-429, 2015.

FREIRE, P. Pedagogia do Oprimido. Rio de Janeiro: Paz e Terra, 2011.

MARCONI, M. A.; LAKATOS, E. M. Fundamentos de metodologia científica. $7^{\text {a }}$ ed. São Paulo: Atlas, 2010.

MERCADO, L. P. L. Novas tecnologias na educação: reflexões sobre a prática. Maceió: Ed. EDUFAL, 2002. 210 p.

MESQUITA, N. A. S.; SOARES, M. H. F. B.; Diretrizes para a formação de professores da educação básica em interface com a Licenciatura em Química: em contexto as possibilidades formativas. Revista Química Nova, v. 37, n. 6, p. 1072-1077, 2014.

NASCIMENTO, R. L.; O Ensino de Química na Modalidade Educação de Jovens e Adultos e o Cotidiano Como Estratégia De Ensino/Aprendizagem, Peabiru, 2012. 13 p. Dissertação (Ensino das Ciências). Faculdade Integrada da Grande Fortaleza, FGF, 2012.

SILVA, O. G.; NAVARRO, E. C. A relação professor-aluno no processo ensinoaprendizagem. Revista Eletrônica Interdisciplinar, v. 2, n. 8, 2012.

SOUZA, J. J. N.; Experimentação no ensino noturno: uma proposta para o ensino de Química, Brasília, 2013. 29 p. Tese de Doutorado. UNIVERSIDADE DE BRASÍLIA. Dissertação de doutorado (Programa de Pós-Graduação em Ensino de Ciências). Universidade De Brasília UNB, 2013.

VAITSMAN, E.P.; VAITSMAN, D.S. Química \& Meio ambiente: Ensino contextualizado. Rio de Janeiro: Interciência, 2006. 